\title{
When Does Giving Voice or Not Matter? Procedural Fairness Effects as a Function of Closeness of Reference Points
}

\author{
DAVID DE CREMER AND JEROEN STOUTEN \\ Tilburg University
}

\begin{abstract}
The present study examined whether manipulating the closeness of reference points can provide further insights into explaining why people care so much about receiving voice (i.e., the opportunity to express one's opinion with respect to allocation decisions). Participants read a scenario portraying a situation where they had always been a member of the relevant team (i.e., distant referent point condition) or where they had just become a member of the relevant team (i.e., close referent point condition). Thereafter, they were either told that they would receive voice or no voice with respect to the issue of distributing a financial bonus. The results showed that people cared more about voice when they were placed in the distant referent condition rather than in the close referent condition. This effect was strongest on participants' positive emotions (i.e., being positive when receiving voice vs. receiving no voice) than on their negative emotions. The findings are discussed in light of procedural fairness, counterfactual thinking, and emotion literature.
\end{abstract}

$\mathrm{S}^{\mathrm{i}}$ ince the seminal work of Thibaut and Walker (1975) it is a pervasive finding that people's fairness judgments are not only influenced by how fair people evaluate the outcomes they receive (distributive justice), but also by how fair they consider the procedures used to determine the outcomes (procedural justice) (Brockner \& Wiesenfeld, 1996; Lind \& Tyler, 1988). A vast amount of studies have demonstrated that perceived procedural fairness positively affects people's evaluations of the outcomes they receive (e.g., Tyler, 1990, Van den Bos et al., 1997). Procedural fairness has also been found to have a positive influence on support and evaluations of authorities (Greenberg, 1987; Tyler \& Lind, 1992; Van den Bos, Wilke, \& Lind, 1998), compliance with authorities (Lind \& Tyler, 1988; Tyler, 1989), behavior (Greenberg, 1987; Moorman, 1991), self-esteem (Koper et al., 1993), and affective reactions such as anger (Folger, 1977). These and other fair process effects have led social justice researchers to conclude that, in addition to distributive justice, procedural justice plays a very important role in the psychology of social justice (Lind \& Tyler, 1988).

Over the years research on the issue of procedural fairness has resulted in an impressive number of experimental studies where procedural fairness is manipulated by allowing participants the opportunity to express one's opinion or not about an allocation decision (see e.g., Brockner et al., 1998; Lind, Kanfer, \& Earley, 1990; Van den Bos, 1999). In fact, it can now be concluded that voice is the most accepted and 
most frequently used manipulation of procedural fairness (e.g., Brockner et al., 1998; Van den Bos, Vermunt, \& Wilke, 1996). Indeed, the powerful implications of voice for enhancing procedural fairness cannot be denied as it is frequently shown that voice is associated with increased procedural fairness perceptions (e.g., McFarlin \& Sweeney, 1996), decision-making (e.g., Lind et al., 1990), goal-setting (e.g., Early \& Lind, 1987) and outcome fairness (e.g., Van den Bos et al., 1997). Despite the fact that there is strong evidence for robust effects of voice on a variety of different human reactions, it is not exactly clear why voice opportunities influence people's reactions.

In a recent article, Van den Bos and van Prooijen (2001) argued that the psychology of reference points (Kahneman \& Tversky, 1982) might help illuminate this question. That is, they started from the assumption that the way people evaluate whether something is fair or not is to refer to relevant reference points (e.g., Cropanzano \& Randall, 1995). For example, earlier theories on distributive justice (e.g., equity theory; Adams, 1965) demonstrated that people use the outcomes of comparison to others as a reference point to determine whether their own outcome can be judged as fair or not (i.e., personal outcomes are regarded as fairer when they are equal, rather than different from the outcomes of those of others). In their attempt to demonstrate the usefulness of reference points in determining people's reactions toward voice manipulations, Van den Bos and van Prooijen used Referent Cognitions Theory (RCT; Cropanzano \& Folger, 1989; Folger, 1986) to make exact predictions regarding the relevance of reference points to the issue of voice. Following RCT, it is suggested that people engage in a type of mental simulation whereby they explore whether or not they may have been able to obtain better outcomes or better procedural treatment (e.g., Cropanzano \& Folger, 1989). This mental activity in turn may influence fairness perceptions and satisfaction ratings. Therefore, Van den Bos and van Prooijen (p. 617) argue that "people's reactions to procedural and distributive justice depend largely on their counterfactual thoughts," that is, the ease for people to mentally simulate a better outcome or procedure than they actually received. This point of view thus suggests that the reference point one takes is important to determine the extent to which one can imagine receiving better or worse outcomes and procedural treatment.

Based on this application of RCT, Van den Bos and van Prooijen (2001) however, argue that prior justice research has only used reference points that explicitly referred to justice-related information. For example, studies using RCT-assumptions always manipulated how easily participants could think of receiving other and more favorable outcomes and procedures. Thus, the referent in such studies referred to the awareness of outcome or procedural alternatives. Because of this reason, Van den Bos and van Prooijen (2001) decided to use reference points that did not refer to justice-related information. Disentangling the nature of the reference point from justice related information (e.g., receiving voice or not) was expected to be a stronger and more valid test for examining the importance of reference points in explaining why people react to voice opportunities. Therefore, to use reference points without justice-related information, Van den Bos and van Prooijen, in their studies, manipulated closeness of reference points. More precisely, their manipulation was based on the approach taken from Kahneman and Tversky's (1982) example of arriving too late at the airport. In this 
example, Kahneman and Tversky describe a story of two people who missed their flight. In half of the conditions, the person missed his flight by 30 minutes (distant reference), whereas in the other condition he missed his flight by five minutes (close reference). Participants thought that the person who missed his flight by five minutes would be most upset.

In a similar vein, participants in the Van den Bos and van Prooijen's (2001) study were told that they worked within an organization consisting of five teams. It was decided that a financial bonus would be distributed among all employees. Participants were then told that they were a member of the blue team (distant reference) or that they had become a member of the blue team that same morning (close reference). Thereafter, participants were informed that they either received voice (i.e., fair procedure) in the decision on how to distribute the bonus or did not receive voice (i.e., unfair procedure). Their results showed that people exhibited stronger negative emotional reactions when they received no voice versus voice, but this was only the case in the close reference point condition and not in the distant reference point condition. Thus, these findings indicate that when people just became a member of the blue team, but missed out on the opportunity to voice their opinion about the allocation of the financial bonus, manipulations of procedural fairness influenced their reactions more strongly. Indeed, under these circumstances, people could have imagined not having received any possibility of voice easier if they would not have changed teams the same morning (i.e., this parallels the close reference condition in Kahneman and Tversky's condition of just missing one's flight). However, some problems may be involved in the study by Van den Bos and van Prooijen.

First, in the Van den Bos and van Prooijen study, the dependent measure was negative affect. Because counterfactual thinking plays an important role in the psychology of reference points, negative affect may not be the best emotional measure. Why? Counterfactual thinking is considered to be a mental simulation about what might have been (see Roese, 1997, for a review). One way of classifying counterfactuals is on the basis of their direction of comparison (Markman et al., 1993; McMullen, 1997; Roese, 1997). People may focus on how the outcome might even have been worse (i.e., downward comparisons). Alternatively, one can also imagine that the actual outcome might have been much better (i.e., upward comparisons). Thus, engaging in counterfactual thinking involves comparing the actual outcome to imaginary alternatives that may be comparatively worse or better. One's emotional or mood experiences seem to be an inherent component of counterfactual thinking. Previous research has convincingly demonstrated that people generate spontaneously far more upward than downward counterfactuals (Nasco \& Marsh, 1999), and that in this process upward comparisons generate more unpleasant negative emotions such as distress, disappointment and self-blame (Davis et al., 1995; Kahneman \& Miller, 1986; Markman et al., 1993). In contrast, when people engage in downward comparisons one experiences more pleasant and positive feelings (McMullen, 1997; Roese, 1994). This effect has been called the affective contrast effect. This effect suggests that feelings and judgments become more extreme when engaging in upward (more negative) or downward (more positive) comparisons. 
The existence of such affective contrast effect implies that Van den Bos and van Prooijen should have examined the interactive effect between closeness of reference points and voice on positive affect (rather than on negative affect). Indeed, in the Van den Bos and van Prooijen study, participants were able to engage only in downward comparisons with respect to their reference point. That is, because in both conditions they were members of the blue team, they were only able to imagine not being a member of the blue team. Therefore, it is important to replicate their study and, in addition to studying negative affect include positive affect. This was the first aim of the present study.

Second, participants may have experienced regret about leaving their former team because people in the close reference point condition were transferred from another team to the blue team. Regret can be defined as "a more or less painful cognitive and emotional state of feeling sorry for misfortunes, limitations, losses, transgressions, shortcomings, or mistakes. It is an experience of felt-reason or reasoned-emotion" (Landman, 1993: 36). Literature on the need to belong shows that people have a strong need to establish social links with others and once established, they are averse to giving up these connections to build up new social relationships (Baumeister \& Leary, 1995; cf. status quo bias). In the study by Van den Bos and Van Prooijen, participants moved to another group and due to people's need to belong, they might have experienced strong emotions of regret. Moreover, as we argued earlier, the situation of moving from their initial team to the blue team will instigate downward counterfactual thinking. One specific emotion related to this type of counterfactual thinking is regret (Roese, 1997). Finally, moving from one's initial team to the other team also involves action and it is suggested that action rather than inaction is assumed to generate more regret (Gilovich \& Medvec, 1994). Therefore, taking into account all these research findings, it seems clear that regret can outshine the interactive effect of reference point and procedural fairness. As such, it is important to control for this specific emotion of regret. This was the second aim of the present study.

To summarize, the present study aims to replicate the study of Van den Bos and van Prooijen (2001) by examining and restoring two potential problems inherent in their research design. First, in addition to assessing negative affect we also included a positive affect scale. Following the findings from Van den Bos and van Prooijen, it was expected that an interaction effect between closeness of reference point and the voice manipulation would be found. However, in line with the counterfactual literature, this interactive effect should reveal stronger effects on positive affect scores rather than on negative affect scores because their research design only allowed for participants to engage in downward counterfactual thinking (i.e., how outcomes might even have been worse). Second, in line with research on the need to belong and counterfactual thinking, the present study will also control for people's feelings of regret about being a member of the blue team. 


\section{METHOD}

\section{Participants and Design}

Thirty-six undergraduate students participated and were paid two euros for their participation (approximately 1.5 U.S. dollars). Participants were randomly allocated to the experimental conditions of a 2 (Closeness reference point: Close vs. distant) x 2 (Procedural fairness: Voice vs. no voice) between-subjects design.

\section{Procedure}

A research assistant, who asked them whether they would be willing to fill out a series of scenario studies, approached participants. Participants were asked to picture that the following story actually happened to them. The same description was used as the Van den Bos and van Prooijen's study. Participants read the following:

You work in an organization. In this organization, people work together in teams. There are five teams within the organization. These teams are described by means of colors: the red team, the blue team, the yellow team, the green team, and the orange team. Because the organization has performed well, it is announced that a bonus of 10000 Dutch Guilders will be distributed among all employees. A certain amount of money has been allocated to your team. The management of the organization has to decide how this amount of money will be distributed.

Thereafter, the manipulation of closeness of reference point was introduced. In half of the conditions, participants were told that they always had been a member of the blue team (i.e., distant reference condition). The other half of the participants were told that yesterday morning they were a member of the red team and that since yesterday evening they were a member of the blue team (i.e., close reference condition). This was followed by the voice manipulation. Participants in the voice condition read that management would ask their opinion, whereas participants in the no voice condition were told that their opinion would not be asked.

Then, the dependent measures were solicited (focusing first on the negative and subsequently the positive emotions; see also Van den Bos \& Miedema, 2000, Experiment 3). First, six negative emotion items were asked. Participants were asked to what extent they were "angry," "disappointed," "sad," "outraged," "annoyed," and "melancholy" with the way that management treated them. These items were combined to form one average negative emotion score (Cronbach's $\alpha=.92$ ). Then, four positive emotion items were asked. Participants were asked to what extent they were "happy," "satisfied," "positive," and "glad" with the way that they were treated by management. These items were combined to form one average positive emotion score (Cronbach's $\alpha$ $=.95)$. Negative and positive emotions correlated negatively, $r=-.60, p<.001$. To 
measure participants' feeling of regret about their group membership, they were asked to what extent they felt regret about their current group membership. All questions were answered on a 7-point scale (ranging from not at all [1] to very much so [7]). Finally, participants were debriefed, paid, and thanked.

\section{RESULTS}

\section{Regret}

A 2 (Procedure: Voice vs. no voice) x 2 (Closeness of the reference point: Close vs. distant) ANOVA on the regret score revealed a significant main effect for closeness of the reference point, $F(1,32)=11.52, p<.005, \eta^{2}=.27$ : Participants in the close reference condition (i.e., who very recently joined the blue group) experienced more regret about their group membership than those in the distant reference condition ( $M \mathrm{~s}$ $=3.63$ vs. 1.95 , and $S D \mathrm{~s}=1.58$ and 1.46 ; respectively). Further, a marginal significant main effect of procedure was found, $F(1,32)=3.32, p<.08, \eta^{2}=.09$. Participants in the no voice condition expressed stronger feelings of regret than those in the voice condition ( $M \mathrm{~s}=3.24$ vs. $2.34, S D \mathrm{~s}=1.90$ and 1.44 ; respectively). No significant interaction effect was found, $F(1,32)=1.47, p<.24, \eta^{2}=.04$.

\section{Positive Emotions}

A 2 (Procedure) $\times 2$ (Closeness of the reference point) ANCOVA on the average positive emotion score, with participant's regret score as a covariate, revealed a significant main effect for the covariate $(\beta=-0.37), F(1,31)=7.87, p<.01, \eta^{2}=.20$. Further, a significant main effect of procedure was found, $F(1,31)=7.87, p<.01, \eta^{2}$ $=.20$ : Participants in the voice condition expressed stronger positive emotions than those in the no voice condition $(M \mathrm{~s}=4.28$ vs. $3.14, S D \mathrm{~s}=1.32$ and 1.28 ; respectively). No main effect for closeness of the reference point was found, $F(1,31)=.05, p$ $<.82, \eta^{2}=.00$. Also, a significant interaction between procedure and closeness of the reference point emerged, $F(1,31)=5.24, p<.05, \eta^{2}=.14$.

Planned comparisons revealed that participants in the distant reference point condition reported significantly higher positive emotions when voice was given than when no voice was given, $F(1,31)=15.65, p<.001$, whereas for those in the close reference point condition no significant difference in emotions was found between the voice and no-voice condition (Table 1$), F(1,31)=0.15, p<.71$.

\section{Negative Emotions}

A 2 (Procedure) $\times 2$ (Closeness reference point) ANCOVA on the average negative emotion score, with participant's regret score as a covariate, revealed a significant main effect for the covariate $(\beta=0.35), F(1,31)=5.13, p<.05, \eta^{2}=.14$. No significant main effect for procedure, $F(1,31)=.99, p<.33, \eta^{2}=.03$, and for closeness of the reference point, $F(1,31)=.00, p=.99, \eta^{2}=.00$, was found. Further, 
TABLE 1

Adjusted Means and Standard Deviations of Emotional Reactions as a Function of Procedure and Closeness of the Reference Point

\begin{tabular}{lllc}
\hline Dependent & & \multicolumn{2}{c}{ Reference Point } \\
\cline { 3 - 4 } Variables & Procedure & Close & Distant \\
\hline Positive Emotions & Voice & $\mathbf{3 . 8 8}(0.96)$ & $\mathbf{4 . 6 7}(1.36)$ \\
& No Voice & $\mathbf{3 . 6 4}(1.10)$ & $\mathbf{2 . 6 4}(1.46)$ \\
\hline Negative Emotions & Voice & $\mathbf{3 . 5 0}(0.84)$ & $\mathbf{2 . 7 4}(1.45)$ \\
& No Voice & $\mathbf{3 . 1 9}(1.69)$ & $\mathbf{3 . 9 3}(1.24)$ \\
\hline
\end{tabular}

Note. Entries in bold are means on 7-point scales, with higher values indicating higher ratings of positive emotions and lower ratings of negative emotions, respectively; entries within parentheses are standard deviations.

only a marginal interaction between procedure and closeness of the reference point emerged, $F(1,31)=2.99, \mathrm{p}=.09, \eta^{2}=.08$.

Planned comparisons revealed that participants in the distant reference point condition reported significantly lower negative emotions when voice was given than when no voice was given, $F(1,31)=4.43, p<.05$, whereas for those in the close reference point condition no significant difference in emotions was found between the voice and no-voice condition, $F(1,31)=0.21, p<.66$.

\section{DISCUSSION}

Taken together, the present results revealed a significant interaction between closeness of the reference point and the manipulation of voice showing that participants reacted most strongly toward variations of voice in the distant reference condition (which is contrary to the findings of Van den Bos and van Prooijen, 2001). Moreover, in line with the counterfactual thinking literature, it was found that this interactive effect revealed the strongest effects on positive emotions relative to negative emotions. In the following paragraphs the theoretical implications will be discussed.

The most important finding was that participants reported significantly higher positive emotions when they received voice (i.e., when they were able to explain their opinions), relative to when they did not receive voice, but only so in the distant reference condition and not (as expected by the Van den Bos and van Prooijen's findings) in the close reference condition. According to the literature on reference points, one is assumed to engage more easily in counterfactual or referential thinking when the reference point is considered to be close (Kahneman \& Tversky, 1982).

How are we to explain this inconsistent finding? One possible explanation may be that people in the distant reference condition, relative to those in the close reference condition, were more positive toward their group membership in the blue team. As such, participants in the close reference condition may have experienced more regret about their new group membership. Although this explanation seems compelling and the results did indeed show that those in the close reference condition experienced more regret about their membership than those in the distant reference condition, it is 
necessary to point out that we controlled for feelings of regret by using it as a covariate in our analyses. Thus, feelings of regret do not seem to account for the observed interaction effect.

Rather, it may be that more specific motives and cognitions related to feelings of group membership may explain why it is that the present findings show that people react more strongly toward variations of voice when they always have been a member of the blue team (i.e., the distant reference point condition). Hence, these members in the distant reference condition might have felt that they were personally entitled to receive voice when deciding how to distribute the bonus and therefore reacted in a positive way when this sense of entitlement was indeed confirmed. Members in this group may thus have felt that they earned the right to be listened to by means of the fact that they belonged to the blue team. However, when these participants did not receive voice, there was a decrease in positive reactions. This finding is in contrast to the findings obtained in the close reference condition where members only joined the group at the very last minute. Here, group members may not have felt that they deserved to receive voice after all, relative to their former group members (i.e., their old members in the red team). This may indeed have happened since the voice manipulation was directed to the individual group member. As such, it may have signaled to this new group member in the blue team that he just arrived in the group and that therefore the decision not to grant voice to this new member should not be so surprising. Indeed, under these circumstances, newcomers may not have felt that they were entitled to receive voice. Future research is required to examine in greater detail the validity of these alternative psychological explanations.

Another interesting finding is that the interaction effect between voice and the closeness of the reference point was found on positive emotions rather than negative emotions. As mentioned earlier, Van den Bos and van Prooijen (2001) measured negative affect in their study. However, in our introduction we argued that, following the literature on directions of counterfactual thinking, it would be better to also assess positive emotions. Indeed, the experimental procedure of the present study and the procedure used in the Van den Bos and Van Prooijen study employed a paradigm in which participants were only able to think about a situation where they would not be a member of the blue team. As a consequence, because they were in the blue team, they could only reflect upon a situation where they definitely would never have received the opportunity to express their opinion (i.e., being in the red team). This type of reflection is referred to as downward counterfactual thinking, and this type of mental simulation is supposed to elicit mainly positive emotions (McMullen, 1997; Roese, 1994). However, it is good to note that the present findings also revealed a marginal effect on negative emotions, but the effect was nevertheless stronger on positive emotions.

Further, it is not only necessary to focus on both positive and negative emotions when testing the effect of counterfactual thinking on reactions to the manipulation of voice. Indeed, it is also necessary to be more precise about the specific emotion under investigation. That is, in experimental research, manipulated variables may influence 
one specific emotion differently than another specific emotion. For example, Zeelenberg, Van Dijk, and Manstead (1998) in two studies demonstrated that feelings of responsibility increased the experience of regret, but at the same time decreased the experience of disappointment. Therefore, in line with Zeelenberg et al. (1998) it is important to realize that "which emotion one measures...has an important bearing on the conclusions one draws regarding the influence of such a factor on emotion" (p. 267). Moreover, it is interesting to note that emotions, and mood in general, does not serve only as a dependent measure resulting from the act of counterfactual thinking, but that mood can also be an important moderator of the type of counterfactual thinking that people produce. Indeed, Sanna, Turley-Ames, and Meier (1999), for example, found that negative mood induced more upward counterfactuals, whereas positive mood leads to more downward counterfactuals. Future research may consider using mood as a moderator when examining the role of counterfactual thinking in understanding the effect of closeness of reference points on emotional reactions.

Before closing, it has to be noted that a limitation in the present study concerns its low power. However, since the present findings align well with the ideas developed in our introduction, we are relatively confident about the validity of the present results. Of course, future research in this research field may benefit from using larger sample sizes. Further, in order to check that participants could imagine that procedures would be different as a function of the closeness of the reference point, future research should also include manipulation checks (although it is fair to note that our manipulations of the closeness of the reference point and voice has already been proven to be successful in prior experiments). Another potential limitation is that we cannot entirely exclude the possibility that participants engaged in upward counterfactuals. Indeed, participants in the close reference condition may have thought that if they did not have to switch to the new blue group, they did not have to deal with the annoying task of allocating a bonus. It seems likely that such a process will be a function of whether participants perceive such a task as an opportunity to strive for financial improvement or as a task that they wish to avoid. Future research may include measures such as the regulatory focus scale (Higgins et al., 2001) to assess promotion versus prevention tendencies or manipulate participants' attitudes toward the task. It is important to note that the present findings are in line with our predictions based on the assumption that participants would engage in downward counterfactual thinking.

To conclude, the present findings show that one way of understanding why people react to voice opportunities the way they do is to focus on the importance of reference points. Reference points allow for mental simulations to take place, and as such to generate better alternative outcomes or procedures, consequently influencing people's reactions. Similar to Van den Bos and van Prooijen's (2001) findings, the present study showed that reference points without any reference to justice-related information exert strong influence on the voice effect. Finally, the present study also points out the importance of identifying clearly the type of emotion under investigation. 


\section{NOTES}

The first author was supported by a fellowship of the Netherlands Organization for Scientific Research (NWO, Grant No. 016.005.019).

Address for correspondence: David De Cremer, Department of Economic and Social Psychology, Tilburg University, P.O. Box 90153, 5000 LE Tilburg, the Netherlands, E-mail: d.deCremer@uvt.nl.

\section{REFERENCES}

Baumeister, R.F., \& Leary, M.R. (1995). The need to belong: Desire for interpersonal attachments as a fundamental human motivation. Psychological Bulletin, 117, 497-529.

Brockner, J., Heuer, L., Siegel, P.A., Wiesenfeld, B., Martin, C., Grover, S., Reed, T., \& Bjorgvinsson, S. (1998). The moderating effect of self-esteem in reaction to voice: Converging evidence from five studies. Journal of Personality and Social Psychology, 75, 394-407.

Brockner, J., \& Wiesenfeld, B.M. (1996). An integrative framework for explaining reactions to decisions: Interactive effects of outcomes and procedures. Psychological Bulletin, 120, 189-208.

Cropanzano, R., \& Folger, R. (1989). Referent cognitions and task decision autonomy: Beyond equity theory. Journal of Applied Psychology, 74, 293-299.

Cropanzano, R., \& Randall, M.L. (1995). Advance notions as a means of reducing relative deprivation. Social Justice Research, 8, 217-238.

Davis, C.G., Lehman, D.R., Wortman, C.B., Silver, R.C., \& Thompson, S.C. (1995). The undoing of traumatic life events. Personality and Social Psychology Bulletin, 21, 109-124.

Folger, R. (1977). Distributive and procedural justice: Combined impact of "voice" and improvement of experienced inequity. Journal of Personality and Social Psychology, 35, 108-119.

Folger, R. (1986). Rethinking equity theory: A referent cognitions model. In M. Bierhoff, R.L. Cohen, \& J. Greenberg (Eds.), Justice in social relations (pp. 145-162). New York: Plenum.

Gilovich, T., \& Medvec, V.H. (1994). The temporal pattern to the experience of regret. Journal of Personality and Social Psychology, 67, 357-365.

Greenberg, J. (1987). Using diaries to promote procedural justice in performance appraisals. Social Justice Research, 1, 219-234.

Higgins, E.T., Friedman, R.S., Harlow, R.E., Idson, L.C., Ayduk, O.N., \& Taylor, A. (2001). Achievement orientation from subjective histories of success: Promotion pride versus prevention. European Journal of Social Psychology, 31, 3-24.

Kahneman, D., \& Miller, D.T. (1986). Norm theory: Comparing reality to its alternatives. Psychological Review, 93, 136-153.

Kahneman, D., \& Tversky, A. (1982). The simulation heuristic. In D. Kahneman, P. Slovic, \& A. Tversky (Eds.), Judgment under uncertainty: Heuristics and biases (pp. 201-208). New York: Cambridge University Press.

Koper, G., van Knippenberg, D., Bouhuijs, F., Vermunt, R., \& Wilke, H.A.M. (1993). Procedural fairness and self-esteem. European Journal of Social Psychology, 38, 504-516.

Landman, J. (1993). Regret: Persistence of the possible. New York: Oxford University Press.

Lind, E.A., Kanfer, R., \& Earley, P.C. (1990). Voice, control, and procedural justice: Instrumental and noninstrumental concerns in fairness judgments. Journal of Personality and Social Psychology, 59, 952 959.

Lind, E.A., \& Tyler, T.R. (1988). The social psychology of procedural justice. New York: Plenum Press.

Markman, K.D., Gavanski, I., Sherman, S.J., \& McMullen, M.N. (1993). The mental simulation of better and worse possible words. Journal of Experimental Social Psychology, 29, 87-109.

McFarlin, D.B., \& Sweeney, P.D. (1996). Does having a say matter only if you get your way? Instrumental and value expressive effects of employee voice. Basic and Applied Social Psychology, 18, 289-303.

McMullen, M. (1997). Affective contrast and assimilation in counterfactual thinking. Journal of Experimental Social Psychology, 33, 77-100.

Moorman, R.H. (1991). Relationship between organizational justice and organizational citizenship behaviors: Do fairness perceptions influence employee citizenship? Journal of Applied Psychology, 76, 845-855.

Nasco, S.A., \& Marsh, K.L. (1999). Gaining control through counterfactual thinking. Personality and Social Psychology Bulletin, 25, 556-568.

Roese, N.J. (1994). The functional basis of counterfactual thinking. Journal of Personality and Social Psychology, 66, 805-818.

Roese, N.J. (1997). Counterfactual thinking. Psychological Bulletin, 121, 133-148.

Sanna, L.J., Turley-Ames, K.J., \& Meier, S. (1999). Mood, self-esteem, and simulated alternatives: Thoughtprovoking affective influences on counterfactual direction. Journal of Personality and Social Psychology, 76, 543-558. 
Thibaut, J.W., \& Walker, L. (1975). Procedural justice: A psychological analysis. Hillsdale, NJ: Erlbaum. Tyler, T.R. (1989). The psychology of procedural justice: A test of the group value model. Journal of Personality and Social Psychology, 57, 333-344.

Tyler, T.R. (1990). Why people obey the law: Procedural justice, legitimacy, and compliance. New Haven, CT: Yale University Press.

Tyler, T.R., \& Lind, E.A. (1992). A relational model of authority in groups. In M. Zanna (Ed.), Advances in Experimental Social Psychology (Vol. 25, pp. 115-191). New York: Academic Press.

Van den Bos, K. (1999). What are we talking about when we talk about no-voice procedures? On the psychology of the fair outcome effect. Journal of Experimental Social Psychology, 35, 560-577.

Van den Bos, K., Lind, E. A., Vermunt, R., \& Wilke, H.A.M. (1997). How do I judge my outcome when I do not know the outcome of others? The psychology of the fair process effect. Journal of Personality and Social Psychology, 72, 1034-1046.

Van den Bos, K., \& Miedema, J. (2000). Toward understanding why fairness matters: The influence of mortality salience on reactions to procedural fairness. Journal of Personality and Social Psychology, 79, 355-366.

Van den Bos, K., \& van Prooijen, J.-W. (2001). Referent cognitions theory: The role of closeness of reference points in the psychology of voice. Journal of Personality and Social Psychology, 81, 616-626.

Van den Bos, K., Vermunt, R., \& Wilke, H.A.M. (1996). The consistency rule and the voice effect: The influence of expectations on procedural fairness judgements and performance. European Journal of Social Psychology, 26, 411-428.

Van den Bos, K., Wilke, H.A.M., \& Lind, E.A. (1998). When do we need procedural fairness? The role of trust in authority. Journal of Personality and Social Psychology, 75, 1449-1458.

Zeelenberg, M., van Dijk, W.W., \& Manstaed, A.S.R. (1998). Reconsidering the relation between regret and responsibility. Organizational Behavior and Human Decision Processes, 74, 254-272. 